\title{
The Person in Transitive and Virtual Space: New Challenges of Modality
}

\author{
Tatiana D. Martsinkovskaya $\mathrm{a}^{\mathrm{a}, \mathrm{b}^{*}}$ \\ a Institute of Psychology, RGGU, Moscow, Russia \\ b Psychological Institute REA, Moscow, Russia \\ *Corresponding author. E-mail: tdmartsin@gmail.com
}

Objective. The aim of this study is to consider the new challenges facing psychological science today, the chief of which are the modern transitive society and network virtual space.

Design. The study consisted of two series of tests. In the first part, 150 students (ages 19-21; 80 female, 70 male) were tested on their structure of social identity and attitudes toward people of both their own and different cultures, with the questionnaires "Structure of social identity," "Level of personal anxiety," and "Attitude to native and alien cultures." In the second part, 100 people were divided into two groups, one of persons 18 to 25 years old, and another of persons 30 to 45 years old. They were asked about their attitudes toward the new technological space with the questionnaire "Attitude to new technological space," which was developed by the author in 2017.

Results. The study showed that transitional space puts people in a difficult life situation, which increases their anxiety and reduces their socialization potential, especially in a multicultural space. The data showed that under these conditions, the family turns out to be the most important group for most people, regardless of their ages or where they live.

Conclusion. A transitive society is determined by its variability, and the uncertainty and multiplicity of social and personal spaces and contexts. This situation raises the status of the family in the structure of sociocultural identity. The experience of working with new technologies is the main determinant of people having a positive attitude toward them.
Keywords: transitive and network space, technological society, picture of the world, methodology. 


\section{Introduction}

The world today can be characterized as a situation where transitivity (variability, multiplicity, and uncertainty) is becoming increasingly widespread, affecting all generations, spheres of life, and social groups (Martsinkovskaya, 2015). One must therefore proceed from the fact that in a transitive society, the plurality of contexts implies, of course, a plurality of approaches to analyzing their psychological content (Roopnarine \& Carter, 1992; Osman, 2018; Pracana \& Wang, 2019). One of the most important approaches, which, along with transitivity, determines the basic patterns of life of modern people, is the network, virtual space.

At the same time, we can assert the ever-increasing influence of the Internet, which is becoming progressively more important in today's changing reality. In fact, we can say that all processes of socialization and identification today are occurring in the transitive world, and that the Internet is gradually becoming one of the most important institutions of socialization, influencing cognitive development, self-realization, and communication (Castells, 1996). Thus, we can say that the patterns that determine the formation of these spaces are, in fact, the patterns of socialization and human development in modern society as a whole. The objective space and time of people's lives in the transitive world are constantly correlated with the subjective construct of space and time that a person creates in the virtual world (Barker \& Bornstein, 2010)). Therefore, an analysis of their relationship will provide an opportunity to identify the difficulties that a person faces in the process of harmonizing two trends of psychological development -socialization and individualization (Borkenau \& Mauer, 2006; DePaulo \& Morris, 2005; Social Psychology in the modern world, 2002).

\section{Rigid and fluid transitivity}

The main characteristics of transitivity are the multiplicity of macro and micro sociocultural contexts, the constant variability of the surrounding world, and uncertainty. At the same time, this uncertainty is largely substantiated by variability, since it is connected with the fact that the changes have many aspects and a fan-like character. In this case, multiplicity is connected, first of all, with the expansion of the multicultural socialization space. Globalization and mass migration increase the cultural, linguistic, and social multiplicity, which further enhances the variability of the seemingly familiar environment.

The difficulty in determining the psychological characteristics of transitivity is related to the fact that a transitive society is, by definition, an interdisciplinary concept. The interdisciplinary character of the concept of "transitive society" is reflected in the differences in the ways sociologists, philosophers, and philologists understand and interpret it. At the same time, when speaking about the peculiarities of socialization and identity in the modern transitive world, it is necessary to turn to this concept's psychological component, which includes not only social transformations, but also their influence on deviations in social values and ideas, and the ambiguity of norms and attitudes.

The modern living space of people around the world is changing rapidly. At the same time, some "islands of stability" remain, which suggests that within the general situation of multiplicity, variability, and uncertainty, two interconnected aspects or phases can be distinguished: 1) rigid or crisis transitivity, and 2) fluid or 
soft transitivity. At the same time, uncertainty, multiplicity, and variability remain the dominant characteristics of the general direction of the development of society, changing the degree of their cardinality.

At the turn of the $21^{\text {st }}$ century, crisis or rigid transitivity dominated the world. There was a sharp transition to new forms of communication and information, and the expansion of migration processes. At the same time, two opposing tendencies, one toward globalization and the other toward isolation of small nations, were growing. All this, together with the economic crisis, led to a change in people's ideas about the world, about permanent, unshakable values, and human technological capabilities (Chan \& Soon, 2011; Bauman, 2016).

It was not without reason that the first serious studies devoted to the psychological characteristics of different generations, including the analysis of new variants of interrelations among peoples of different cultures and nations with each other, appeared in the 1990s (Bauman, 2017). This was the very time when the concept of tolerance and ethnic identity was expanded. Such phenomenology indicates that the period between 1990 and 1995 can be characterized as a period of rigid transitivity (Andreeva, 2002; Arthur, 2001).

Today we can speak about fluid transitivity, which is characterized by a melting, slow but constant change in many aspects of life. That is, the period of cardinal transformations of the 1990s has been replaced by a period of constant slow changes. As a result, transformations become less radical, but remain as inevitable as they were 20 years ago (Martsinkovskaya, 2015).

From a psychological point of view, it is possible to say that crisis or rigid transitivity is a specific shock situation for people, placing increased demands on their viability and emotional stability. But psychologically, such a crisis is viewed as a passing phenomenon that must be dealt with, one which causes emotional distress in the here and now. This variant of transitivity gives hope that if we endure this unfavorable moment, then everything will be fine and stable; everything will return to normal.

On the other hand, fluid transitivity is psychologically much more difficult, as it is a transition to continuous transitivity, not to a period of stability. Changes are ongoing, varying people's lives, values, communication, information, and technological environment. In this case, people understand that these changes are inevitable and unstoppable. Such a long-term sociocultural variability leads to the actualization of the desire for peace and stability. People are tired of uncertainty (transitivity); they want to hide from it in everyday life, such as in a family, or a group of people close to them in values and aspirations (Certeau, 2013; Grishina, 2017).

\section{Network, virtual and transitive society}

The connection between network, virtual, and transitive spaces appears, first of all, in the uncertainty and multiplicity of contexts, groups, languages, and variants of identity. The uncertainty of these spaces is closely related to variability. The criteria by which people evaluate themselves and present themselves to others are constantly changing. Nowadays we have such criteria as "likes" and reposts on the network, and social status or number of citations (h-index) in reality. At the same time the number of socialization groups remains a stable and important indicator of a person's status both in the transitive real society and in a network. 
Along with different types of transitivity, one can also talk about different forms of virtuality, on-line and off-line. You can also speak about the association between rigid transitivity and on-line situations. They are similar because, in both cases, it is difficult to change something once it's done; it is necessary to quickly respond to a situation, and the consequences of quick reactions are often irreversible. From this point of view, there is a certain similarity between fluid transitivity and being off-line in virtual space. Here one can gradually change one's reactions, estimations, and standards. Therefore, these situations are reversible to some extent, although it is still necessary to remember that the situation is changing. And uncertainty, multiplicity, and variability still dominate the general direction of the development of both spaces, changing the degree of their cardinality.

Therefore, the problem of overcoming the psychological and emotional discomfort and tension, a process which is essential for positive socialization in these spaces, is being actualized.

\section{Method}

The study used the questionnaires "Structure of social identity," "Level of personal anxiety," Attitude to native and alien cultures," and "Attitude to new technological space" (Martsinkovskaya, 2017).

\section{Participants}

The study consisted of two series of tests. In the first part 150 students were tested on the structure of their social identity and personal anxiety, as well as their attitudes toward people of both their own and a different culture. In the second part, 100 participants were divided into two groups, one of people 18 to 25 years old, and one of people 30 to 45 years old. They were asked about their attitudes toward the new technological space. Both groups were divided into people who worked with new technologies $(1 \mathrm{~A}, 2 \mathrm{~A}, \mathrm{n}=50)$ and those who didn't have much experience with such work $(1 \mathrm{~B}, 2 \mathrm{~B}, \mathrm{n}=50)$.

All the participants gave their consent to participate in the study.

\section{Results}

\section{Transitivity as a complex life situation}

It can be stated that different aspects of transitivity are associated with different personal difficulties. Thus, variability and uncertainty are associated with the violation of the integrity of one's identity, both in its individual components, and its temporal perspective. The multiplicity makes it difficult for a person to choose a group identification and his/her direction, or the space of socialization.

Thus, we can say that the condition of transitivity can be considered a difficult life situation for most people, and thus requires various coping strategies.

A comparative analysis of what factors influence a person's choice of coping strategy in a stable or transitive society makes it possible to identify some important differences. In a stable situation, the choice of a coping strategy depends mainly on individual and personal characteristics and the social situation. At the same time, 
an individual's values and norms of behavior, including behavior in difficult situations, are transmitted in the process of socialization from older to younger people. In a transitive society, the process of transferring knowledge is very flexible, in accordance with the laws of "liquid" socialization, and depends not only on the micro space, but also on the macro space, such as the spaces of large and small cities.

In a stable society, the level of complexity of a person's life situation is estimated based on the degree of heterochrony, and the imbalance of the social and personal parameters of the chronotope. In the transitive world, this heterochrony is always present, so the complexity of the situation is estimated depending on its ratio within the individual's personal space and time as a whole. In this context, it is necessary to emphasize that, for the study of constantly changing interrelations of time and space, the construct of a person's psychological chronotope is most adequate, as will be discussed more detail below.

Thus, we can state that in a stable society, the choice of options for coping strategies depends on such personal qualities as emotiveness, locus of control, intentionality, and, in part, general intelligence.

In a transitive society, the choice of coping strategies depends on the relationship between one's personal and socio-cultural identity, tolerance for uncertainty, cognitive complexity, and flexibility.

In a stable society, an emotionally colored and personally relevant experience is of great importance; in an informational and transitive society, along with one's own experience, impersonal and generalized information begins to play an increasingly important role.

The fact that a complex multicultural transitive society is a complex situation that causes difficulties and emotional discomfort in the process of socialization is also proven by the study of the structure of sociocultural identity (See Table 1).

Table 1

Structure of social identity

\begin{tabular}{lcc}
\hline \multicolumn{1}{c}{ Social identity } & $\begin{array}{c}\text { Number } \\
\text { of points }\end{array}$ & $\begin{array}{c}\text { Placed } \\
\text { by priority }\end{array}$ \\
\hline I, as part of the family & 79 & $\mathbf{1}$ \\
I, as a representative of my gender & 147 & $\mathbf{2}$ \\
I, as a representative of my generation & 169 & $\mathbf{3}$ \\
I, as a citizen of my country & 171 & 4 \\
I, as a representative of my nationality & 189 & 5 \\
I, as a representative of my profession & 191 & 6 \\
I, as a native speaker & 194 & 7 \\
I, as a resident of my city & 206 & 8 \\
I, as a representative of my culture & 209 & 9 \\
I, as a representative of group of my hobbies & 210 & 10 \\
I, as a representative of humanity & 215 & 11 \\
\hline
\end{tabular}


A comparative analysis of our data shows that in the current situation, the family turns out to be the most important group of reference for most people, regardless of their ages or where they live. Apparently, this is due to the fact that in transitivity the most stable group remains the family, which plays the role of both shelter and support.

The next most important rankings are occupied by the groups " $\mathrm{I}$, as a representative of my generation," "I, as a representative of my gender," and "I, as a citizen of my country." Identification with a large group may also indicate people's desire to find support from a significant, but poorly structured community (boys/girls, citizens). Such an identity creates the illusion of community and emotional support from the majority. The fact that the group is informal and often not personalized does not destroy this illusion, which is often dispelled during actual contacts with specific representatives of the large group.

The leading role of the family as a group of socialization increases substantially for all respondents who have moved to another country. It can be assumed that the role of the family as a source of emotional defense and support in the changed, that is, rigid transitivity, increases significantly, providing the emotional comfort necessary for positive socialization. Also important is the fact that, with a relatively stable role of ethnic identity, the role of linguistic identity increases significantly in a situation of changes in the socio-cultural environment. This fact may indicate that, in a situation of rigid transitivity, language, as a phenomenon of one's native culture, can, like the family, fulfill the role of emotional protection. Identification with one's age group remains consistently high.

In general, we can state the dominance of social emotions associated with the desire to "hide" from the difficulties that always arise in the process of socialization, especially in a complex and changing world. At the same time, the individual emotions that help a person to find support in interests and hobbies (i.e., personal individuality) are expressed very little. A negative characteristic of transitivity is also the high level of anxiety exhibited in many young people (See Figure 1).

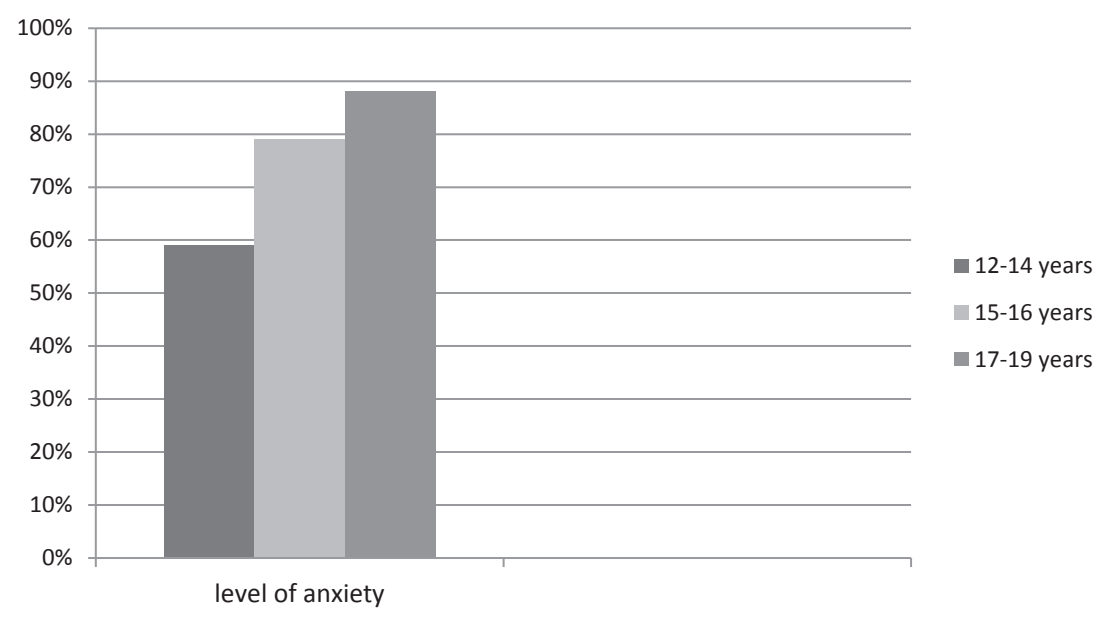

Figure 1. The overall level of personal anxiety. 
The sense of uncertainty is connected with ambiguity about the desired future. Young people's great fear and distress is especially associated with concern about their material well-being in the future, as well as the possibility of achieving their desired role identity. Young boys and girls are less worried about self-realization, i.e., the opportunity to find themselves in interesting and creative activities. Boys, unlike girls, have very little interest in their future family lives.

\section{Representations of native and alien cultures in the picture of the world}

Previous works have studied the general level of ethnocentrism (Martsinkovskaya, 2015; Pracana \& Wang, 2019). Here we present the average data obtained in different regions.

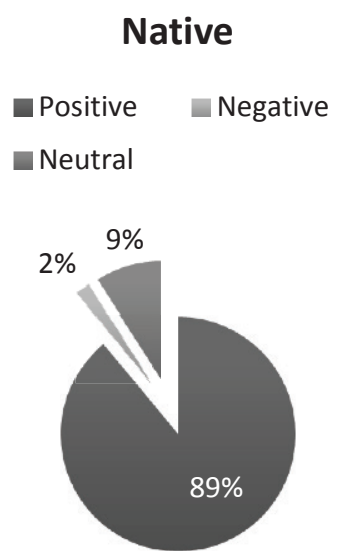

Figure 2. People of my native culture

\section{Foreign culture}
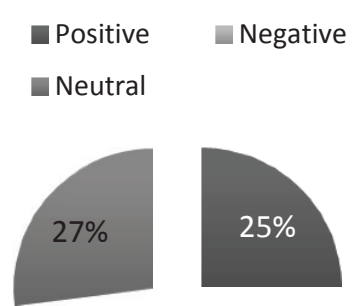

$48 \%$

Figure 3. People of foreign culture

As can be seen from the data, the majority of respondents rated people of their own culture and nationality significantly higher than people belonging to other, especially unfamiliar, cultures.

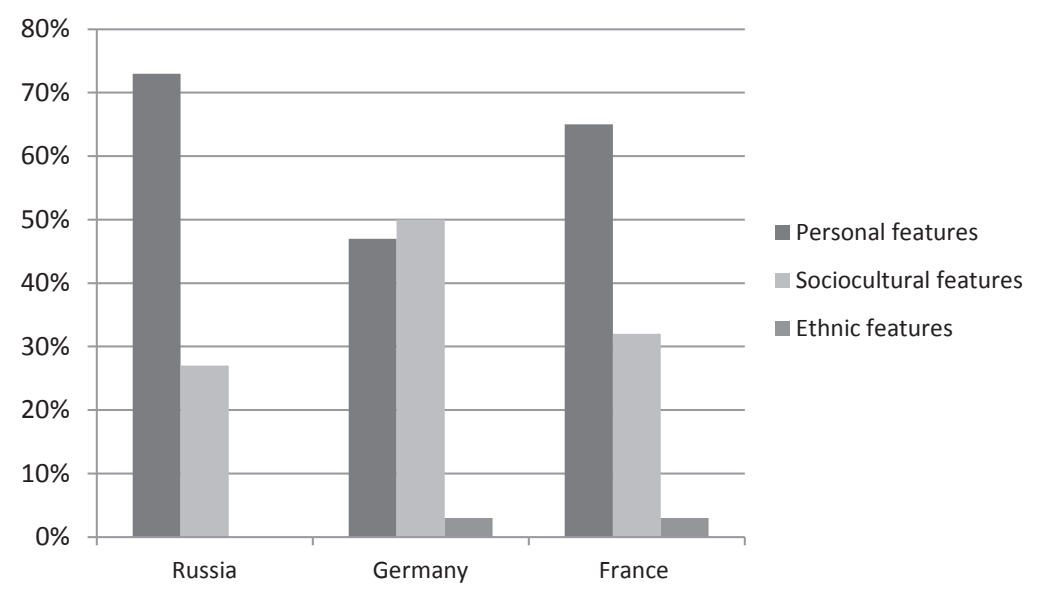

Figure 4. How I am judged by people of my own culture 
At the next stage of the study, the participants were asked to answer the question of by what characteristics they are judged by people from their own or a foreign culture.

As can be seen from the results (See Figure 4), people assume that representatives of their own culture can esteem their individuality and evaluate them, proceeding, first of all, from their personal characteristics rather than their role or sociocultural characteristics. It is remarkable that in Russia, when assessing people of their native culture, people do not consider ethnic characteristics, which, albeit to a small extent, are present when people of another culture are judged. It is also interesting that in Germany the personal and sociocultural characteristics are almost equally present.

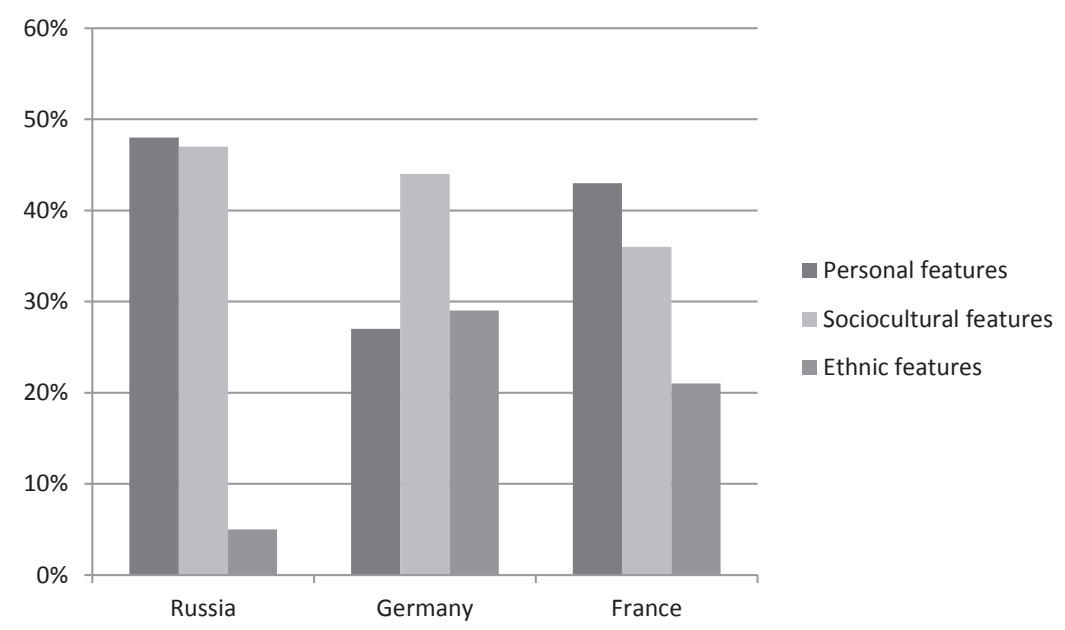

Figure 5. How I am judged by people of a foreign culture

No less interesting are the results of the answers to the second question (See Figure 5). The majority of respondents believe that people of a different culture will see them as personalities, not representatives of another, alien large group. Despite a significant increase in assessments related to ethnicity, personal and sociocultural characteristics also dominate. Thus, we can say that the evaluation of people of a different nationality is affected by the typical effects of the psychology of social cognition.

\section{The attitude toward the new technological space}

At present, we can assert that we are in the midst of civilizational, not only social, change, which is associated with the emergence of not just a new technique, but a new technology, a new technological space (Castells, 1996; Marcus, Machilek, \& Schütz, 2006; Berzonsky, 2008; Martsinkovskaya, 2018). New technologies have become an integral part of modern life, and their influence is becoming more extensive and comprehensive. We are entering a different era, perhaps a new era of civilization, whereby technological society has already passed to a stage in which technology is not external to humans. Man now perceives machines not so much as mechanisms or simple tools, but as part of our environment, often as a continuation of our mental abilities. Apparently, one can say that technical means are internalized by 
people, determining their specific perception of the world, interaction with objects, and communication with others. Modern means of communication and movement have transformed both the space-time continuum itself and our understanding of it. Indeed, we are no longer able to predict the results of the impact of our words, since the response to our words may return to us in a completely different dimension, in another part of the world, in another language.

One of the main bases for this development is the existence of social networks. It can be stated that any social network is perceived by the majority of users as a personal page with its unique and carefully stored content: status, videos, photos, and texts. This page actually becomes a reflection of the world-image of the modern youth. Therefore, it is important to understand not only the causes of the expanding space of social networks in people's image of the world, but also their development trends.

The value of social networks is connected with several factors:

- They help to remove (or significantly reduce) communication barriers (both personal and social);

- They expand the borders of an individual's world-image, constructing new pictures of reality;

- They help provide a "virtual experience" and support for deciding whether I want to get this experience in reality;

- They give people the opportunity to match the modern pace of life.

Our research material shows that modern social networks fulfill both young people's need for information and contacts, and their need for emotional saturation.

Based on the analysis of social networks, it can be assumed that in the near future, due to the spread of high-speed and affordable Internet, social networks will be focused not only on pages in popular groups, but on streaming video. The online broadcast gives the user a unique opportunity to participate in the many different events which take place at the same time. The streaming video will probably soon be replaced by virtual and augmented reality systems.

The transformations of the psychological phenomenology and psychological regularities about the world, and the attitudes towards a new reality that occur in a modern technological society, pose new goals for psychology. These new tasks are connected with investigation of the factors that determine people's acceptance or rejection of new technologies and a new socio-cultural space.

That's why it is very important to analyze the attitude of different age groups (people aged 18 to 25 years and 30 to 45 years) to the new technological space. Both groups were divided into people who worked with new technologies $(1 \mathrm{~A}, 2 \mathrm{~A}, \mathrm{n}=50)$ and those who didn't have much experience with such work $(1 \mathrm{~B}, 2 \mathrm{~B}, \mathrm{n}=50)$.

The study's results about the tolerance of new information technologies showed that in the groups which were connected with new technologies (1A, 2A), 96\% of respondents, regardless of their age, demonstrated a positive attitude toward the new informational space. Respondents from group B showed a lower level of tolerance of new technologies, and there were some differences in the answers according to age: $1 \mathrm{~B}$ showed $63 \%$ tolerance, and 2B 54\% tolerance.

More revealing were the answers about attitudes toward various characteristics of the technological space (see Table 2). 
Table 2

Tolerance of various characteristics of technological space

\begin{tabular}{lcccc}
\hline & \multicolumn{4}{c}{ Characteristics of the technological space } \\
\cline { 2 - 5 } Participants & Internet \% & $\begin{array}{c}\text { Medical } \\
\text { techniques \% }\end{array}$ & $\begin{array}{c}\text { Communication } \\
\text { and movement \% }\end{array}$ & $\begin{array}{c}\text { Robots } \\
\%\end{array}$ \\
\hline Group I A & 89 & 66 & 89 & 43 \\
Group I B & 88 & 52 & 88 & 21 \\
Group II A & 62 & 82 & 67 & 40 \\
Group II B & 39 & 81 & 51 & 7 \\
\hline
\end{tabular}

We can see that the young respondents (group A) actually identify communication and information with the Internet. The overwhelming majority have a positive assessment of these elements of the technological space. In group B there is a division between communication and the Internet, the attitude toward which, especially among people who have little to do with the Internet, is ambivalent, and often even negative. On the contrary, the achievements of medicine are more positively assessed by adults, perhaps due to the fact that they are beginning to think about future treatment. It is interesting that all respondents, even those who deal with automated types of production, were hardly tolerant of robotics. Their negative assessments were mainly connected with moral aspects, but in practice, there were no answers based on purely technical assessments (for example, facilitate the work) or fears about the possibility of losing a job. Thus, it can be said that most people's general idea of a technological society is coherent with ideas about the Internet, while an understanding of the complex multidimensional reality associated with the development of technologies is only realized by a small number of people, mainly those who are professionally associated with it.

\section{Discussion}

Modern reality can be viewed as a complex, multidimensional space-time construct, including external, social, and personal individual spaces, as well as objective and subjective time parameters. The psychological essence of this construct is associated with the subjective attitude towards its components, expressed in people's social and personal emotional experiences, values, and intentions.

Ideas about the heterochrony of the psychological chronotope are extremely important in investigations of modern space-time, which is characterized by its inclusion in the information-network space and technological society. Technologies enhance the chronotope heterochrony, as they can significantly change the direction and speed of interaction of people with each other, objects, and information.

Taking into account the fact that under modern conditions, transitive and virtual spaces are connected, it can be said that psychology must use a complex methodological construct that goes beyond the framework of one methodological system, and represents a kind of methodological collage. 
This methodological collage can be presented as a variant of a large system in which it is important to understand the individualization of results: that is, to build a model in which there is always an inverse relationship between the phenomenon and the interpreter. In addition to including different types of transitivity in a new enlagered methodological construct, the Internet and modern transitive reality spaces must be connected. At the same time, it is necessary to take into account the relationship between external, social, and internal subjective space-time (external and internal forms of psychological chronotope). The important mechanism in this new construct will remain the concept of emotional experience.

\section{Conclusion}

The current situation, in which transitive and virtual spaces are combined, has become the main challenge of modernity. A transitive society is determined by the variability, uncertainty, and multiplicity of social and personal spaces and contexts,

The increased heterogeneity between time and space in the social and personal dimension, which is one of the central laws of the transitive and virtual space, makes it adequate to use the construct of the psychological chronotope for carrying out theoretical and empirical research. The combination of the external and internal forms of the psychological chronotope, with the acceptance of the two levels of determination of psychological development, is productive in the current situation.

Transitional space is a difficult life situation for many people. It reduces the socialization potential of respondents in a multicultural space. It can be assumed that uncertainty and variability increase the heterochrony of both the social and the personal chronotope in a multicultural rather than in a mono-cultural space.

In the situation of both rigid and fluid transitivity, the need for emotional protection and comfort increases. This fact raises the status of the family in the structure of socio-cultural identity.

Given that the new cultural environment is poorly understood and difficult for many people, an important point in the new methodology will be the operationalization of the psychology of everyday life as a way of coping with the new challenges. Everyday life will be considered a specific strategy for coping with the multiplicity and variability of contexts, making it possible to restore identity and integrity to one's daily life.

We must also consider the fact of a significant discrepancy between the way people assess specific people from a foreign culture, and their overall assessment and attitude toward a large group of people from a different culture and language. It can be assumed that the fact of ethnocentrism is associated with different content of a culture's structural links, which opens ways for constructing a model of complementary, corresponding, and orthogonal cultures.

\section{References}

Andreeva, G.M. (Ed.) (2002). Sotsial'naya psikhologiya v sovremennom mire [Social Psychology in the modern world]. Moscow: Aspect-press

Arthur, N. (2001). Using critical incidents to investigate cross-cultural transitions. International Journal of Intercultural Relations, 25, 41-53. https://doi.org/10.1016/S0147-1767(00)00041-9 
Barker, E.T., \& Bornstein, M.H. (2010). Global self-esteem, appearance satisfaction, and selfreported dieting in early adolescence. The journal of early adolescence, 30(2), 205-224. https://doi.org/10.1177/0272431609332936

Bauman, Z. (2016). Strangers at our door. Cambridge: Polity Press.

Bauman, Z. (2017). Retrotopia. Cambridge: Polity Press. https://doi.org/10.14515/monitoring.2018.6.22

Berzonsky, M. (2008). Identity formation: the role of identity processing style and cognitive processes. Personality and Individual Differences. 44, 645-655. https://doi.org/10.1016/j. paid.2007.09.024

Borkenau, P., \& Mauer, N. (2006). Personality, emotionality and risk perception. Journal of Individual Differences, 27(3), 127-135. https://doi.org/10.1027/1614-0001.27.3.127

Castells, M. (1996). The Rise of the Network Society: The Information Age: Economy, Society, and Culture. Oxford: Blackwell Publishers.

Certeau, de M. (2013). Sozdaniye povsednevnoy zhizni [Creating the everyday life]. SPb.: Izd-vo Evropeiskogo universiteta v Sankt-Peterburge.

Chan-Hoong, L., \& Soon, D.A. (2011). Study of Emigration Attitudes of Young Singaporeans. Institute of Policy Studies, IPS Working Papers, (19). Retrieved from https://lkyspp.nus.edu.sg/docs/default-source/ips/wp-19_a-study-on-emigration-attitudes-of-young-singaporeans-(2010).pdf

DePaulo, B., \& Morris, W. (2005). Singles in society and science. Psychological Inquiry, 16(2), 57-83. https://doi.org/10.1080/1047840X.2005.9682918

Grishina, N.V. (2017). Povedeniye v povsednevnosti: zhiznennyy stil', povsednevnaya kreativnost' i «zhiznetvorchestvo» [Everyday behavior: life style, everyday creativity and life design]. Psychological study, 10(56), 2. Retrieved from URL: http://psystudy.ru

Marcus, B., Machilek, F., \& Schütz, A. (2006). Personality in cyberspace: personal Web sites as media for personality expressions and impressions. Journal of Personality and Social Psychology, 90(6), 1014-1031. https://doi.org/10.1037/0022-3514.90.6.1014

Martsinkovskaya, T.D. (2018). Psychological aspects of technological society. Psychological study, 11(62), 12. Retrieved from http://psystudy.ru/index.php/eng/2018v11n62e/1666-martsinkovskaya62e.html

Martsinkovskaya, T.D. (2015). Problema sotsializatsii $v$ istoriko-geneticheskoy paradigme [The problem of socialization in the historical-genetic paradigm]. Moscow: Smisl.

Martsinkovskaya, T.D. (Ed.) (2017). Identichnost' $v$ povsednevnom $i$ transitivnom mire [Identity in everyday and transitive world]. Moscow: MPGU Press

Osman, K. (Ed.). (2018). Socialization. Rijeka, Croatia: InTechOpen.

Pracana, C., \& Wang, M. (Eds.). (2019). Psychological Applications and Trends, Lisboa, Portugal: InScience Press

Roopnarine, Jaipaul L., \& Carter, D. Bruce (Eds.). (1992). Parent-child socialization in diverse cultures. Norwood. New Jersey: Alex publishing corporation.

Original manuscript received January 15, 2019

Revised manuscript accepted March 04, 2019

First published online June 15, 2019

To cite this article: Martsinkovskaya, T.D. (2019). Person in Transitive and Virtual Space: New Challenges of Modality. Psychology in Russia: State of the Art, 12(2), 165-176. DOI: 10.11621/pir.2019.0212 